\title{
Diagnostic examination of the child with urolithiasis or nephrocalcinosis
}

\author{
Bernd Hoppe • Markus J. Kemper
}

Received: 28 August 2008 /Revised: 13 November 2008/Accepted: 13 November 2008 /Published online: 23 December 2008

(C) IPNA 2008

\begin{abstract}
Urolithiasis and nephrocalcinosis are more frequent in children then currently anticipated, but still remain under- or misdiagnosed in a significant proportion of patients, since symptoms and signs may be subtle or misleading. All children with colicky abdominal pain or macroscopic hematuria should be examined thoroughly for urolithiasis. Also, other, more general, abdominal manifestations can be the first symptoms of renal stones. The patients and their family histories, as well as physical examination, are important initial steps for diagnostic evaluation. Thereafter, diagnostic imaging should be aimed at the location of calculi but also at identification of urinary tract anomalies or acute obstruction due to stone disease. This can often be accomplished by ultrasound examination alone, but sometimes radiological methods such as plain abdominal films or more sensitive nonenhanced computed tomography are necessary. Since metabolic causes are frequent in children, diagnostic evaluation should be meticulous so that metabolic disorders that cause recurrent urolithiasis or even renal failure, such as the primary hyperoxalurias and others, can be ruled out. The stone is not the disease itself; it is only one serious sign! Therefore, thorough and early diagnostic examination is mandatory for every infant and child with the first stone event, or with nephrocalcinosis.
\end{abstract}

\footnotetext{
B. Hoppe $(\square)$

Department of Pediatrics, Division of Pediatric Nephrology, University Children's Hospital Cologne,

Kerpenerstr. 62,

50924 Cologne, Germany

e-mail: bernd.hoppe@uk-koeln.de

\section{J. Kemper}

Department of Pediatrics, Division of Pediatric Nephrology, University Hospital Medical Center Hamburg-Eppendorf, Hamburg, Germany
}

Keywords Urolithiasis · Nephrocalcinosis · Children · Diagnostics

\section{Introduction}

Different incidence rates and aetiological factors are reported in children with urolithiasis or nephrocalcinosis, reflecting differences in geographic, genetic and socioeconomic background as well as the source of the series and the study design [1].

While the exact rates for nephrocalcinosis are unknown, the incidence of urolithiasis in childhood is believed to be approximately $10 \%$ of that in adults, which is around $5 \%$ in industrialized countries [2]. Since a significant proportion of patients remains undiagnosed or misdiagnosed (incidental discovery reported in 15-40\%), numbers should be interpreted with caution [3]. In specific parts of the world prevalence rates are significantly higher and compare to those of adults [4]. Urolithiasis appears in all pediatric age groups, but a male predominance analogous to that in adult patients is observed. However, urolithiasis in childhood differs substantially from that in adults with regard to aetiology, symptoms and signs, imaging techniques and treatment $[5,6]$. Approximately $40 \%$ of children with urolithiasis have a positive family history of kidney stones, and most of the children have a metabolic background of stone disease. Hence, specific and intensive diagnostic examination is necessary for every child experiencing even a single kidney stone event, to prevent recurrence of disease or even a disastrous outcome with kidney failure and end-stage renal disease [7].

Systematic diagnostic evaluation starts with a detailed medical history, followed by careful imaging studies (primarily avoiding plain X-ray) and specific urine analysis 
strategies. All diagnostic steps lead way to the determination of the pathophysiological background of stone disease [8], in order to initiate early and appropriate treatment to prevent recurrence. In this respect it always has to be kept in mind that kidney stone(s) or nephrocalcinosis are the sign (s) of the disease, but not the disease itself! The following teaching paper details the necessary steps of diagnostic examination of the child with stones or nephrocalcinosis. The stepwise procedure is also shown in Table 1.

\section{Medical history}

Obtaining a thorough medical history followed by a careful physical examination seems to have become a lost art, but it is indispensable for early and correct diagnosis. It is important to obtain information from the family on stones, hematuria and renal failure, and on metabolic diseases (draw a pedigree chart). Particular attention has to be paid to nutrition or specific diets, fluid intake (dehydration), medications (vitamins D/A, steroids, diuretics, etc.), immobilization, and any mineral supplementation. Children with chronic bowel disease (e.g. Crohn's disease, cystic fibrosis, post-bowel resection), neurologic disorders (anti-convulsant drugs, low fluid intake) or with anomalies of the urinary tract predisposing to urine stasis and urinary tract infection (neurogenic bladder, ileal loops, megaureter, megacalycosis, hydonephrosis) are at special risk for stone formation (Table 2).

\section{Clinical findings (physical examination)}

Symptoms of urinary tract stones are often non-specific, particularly in infants and young children [5,9]. In addition, stones may remain asymptomatic for long periods of time. The most common symptom of urolithiasis is abdominal pain, in older children clearly identifiable as colicky pain, in infants and children, however, only recognized as "non-specific" abdominal pain and thus difficult to differentiate from acute appendicitis, etc. [10]. Unexplained sterile pyuria or recurrent urinary tract infections (UTIs) should raise the level of suspicion for urolithiasis, especially in the younger child. Gross or microscopic - non-glomerular - hematuria and, more rarely, flank tenderness or urinary retention are other symptoms encountered. Gross hematuria may be present for some time before urolithiasis or nephrocalcinosis become manifest. Sometimes there are secondary gastro-intestinal tract symptoms such as vomiting, flatulence or constipation.

Symptoms differ according to the location of the stone. Stones of the lower urinary tract may manifest themselves by dysuria, voiding problems or complete urine retention, but enuresis, frequent voiding, hematuria and fever may also be diagnostic hints. Also, manipulation of genitals in younger children may be a first sign of urolithiasis of the urethra. In infants, especially, stones may become stuck and therefore palpable in the urethra, such that the first symptom of stones is inability to pass urine [5]. Stones may even be the first symptom in polycystic kidney disease, especially in the autosomal dominant form, and hence palpable kidneys may lead way to diagnosis.

A missed diagnosis may have serious consequences. For example, diagnosis of primary hyperoxaluria is often only made after end-stage renal failure has occurred years or decades after the first symptom of nephrolithiasis had appeared [11].

In contrast to nephrolithiasis, nephrocalcinosis is mostly asymptomatic, especially during infancy and early child-

Table 1 Diagnostic steps in urolithiasis (UTI urinary tract infection, CT computed tomography, MRI magnetic resonance imaging, PTH parathyroid hormone, $\mathrm{pCO}_{2}$ partial pressure of carbon dioxide)

\begin{tabular}{ll}
\hline Step & Diagnostic findings \\
\hline History, including family history & Diet, fluid intake, medication, vitamin supplementation \\
& Chronic diseases? Malabsorption syndromes? \\
& Immobilization? \\
& Pain, hematuria, vomiting, UTI \\
Clinical findings & Passage of stones, gravel \\
& Ultrasonography, (plain film) \\
Imaging & Non-contrast-enhanced CT, (MRI) \\
& (Intravenous urography) \\
& Density, specific gravity (osmolality), pH, glucose, protein, sediment, culture \\
& Spot urine: molar creatinine ratios of calcium, oxalate, uric acid, citrate, magnesium \\
Urine & Cystine screening (nitroprusside test, amino acid screen) \\
& 24 hour urine: volume, pH; (lithogenic and stone-inhibitory parameters); calculation of urinary saturation \\
& Electrolytes, calcium, phosphorus, magnesium, creatinine, urea, uric acid, alkaline phosphatase, (PTH, \\
Blood/serum & vitamins D/A, plasma oxalate, serum vitamin B6 level) \\
& Acid-base status (pH, pCO ${ }_{2}$, base excess and/or standard bicarbonate) \\
Infrared spectroscopy or X-ray diffraction \\
\hline
\end{tabular}




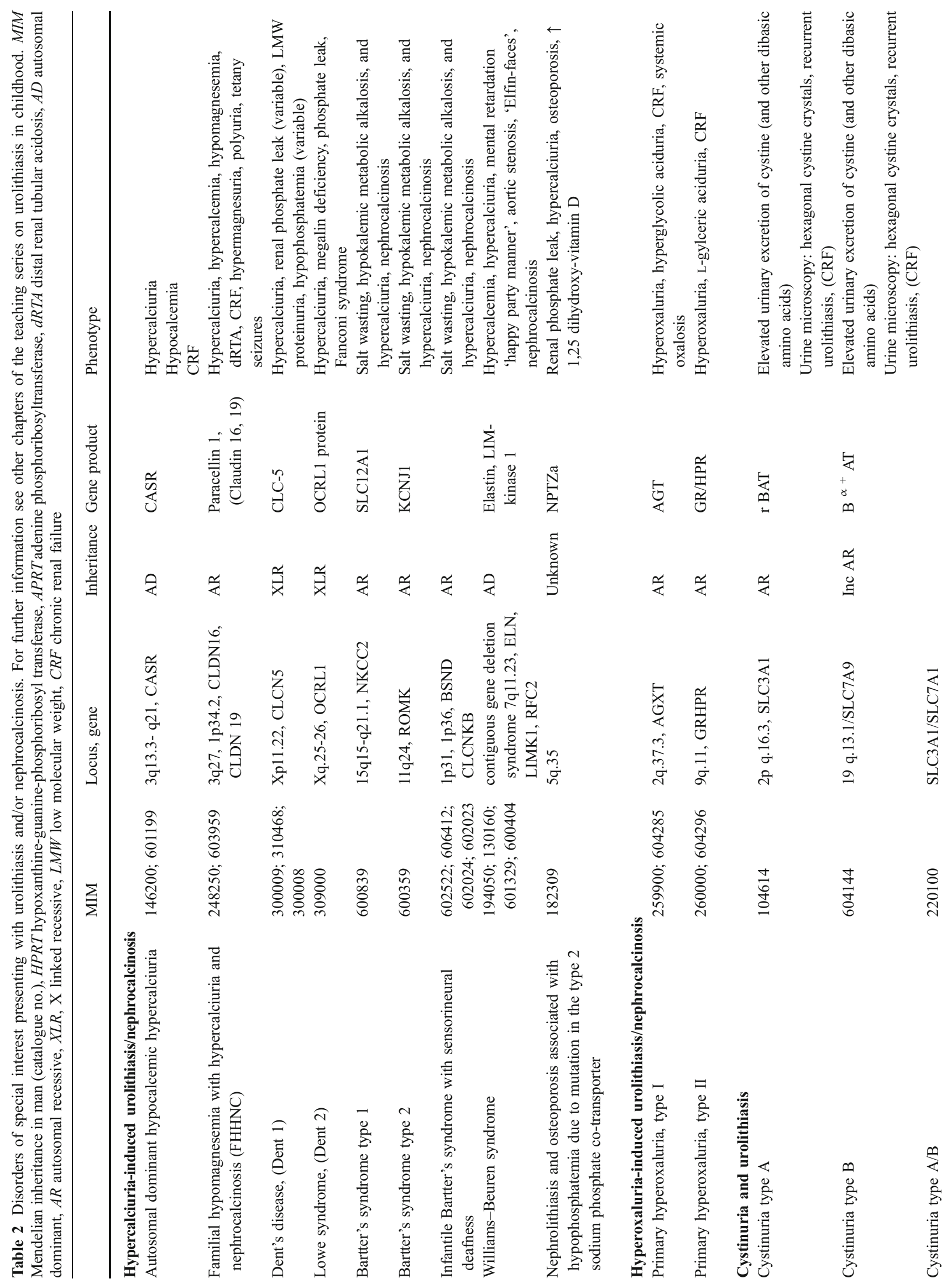




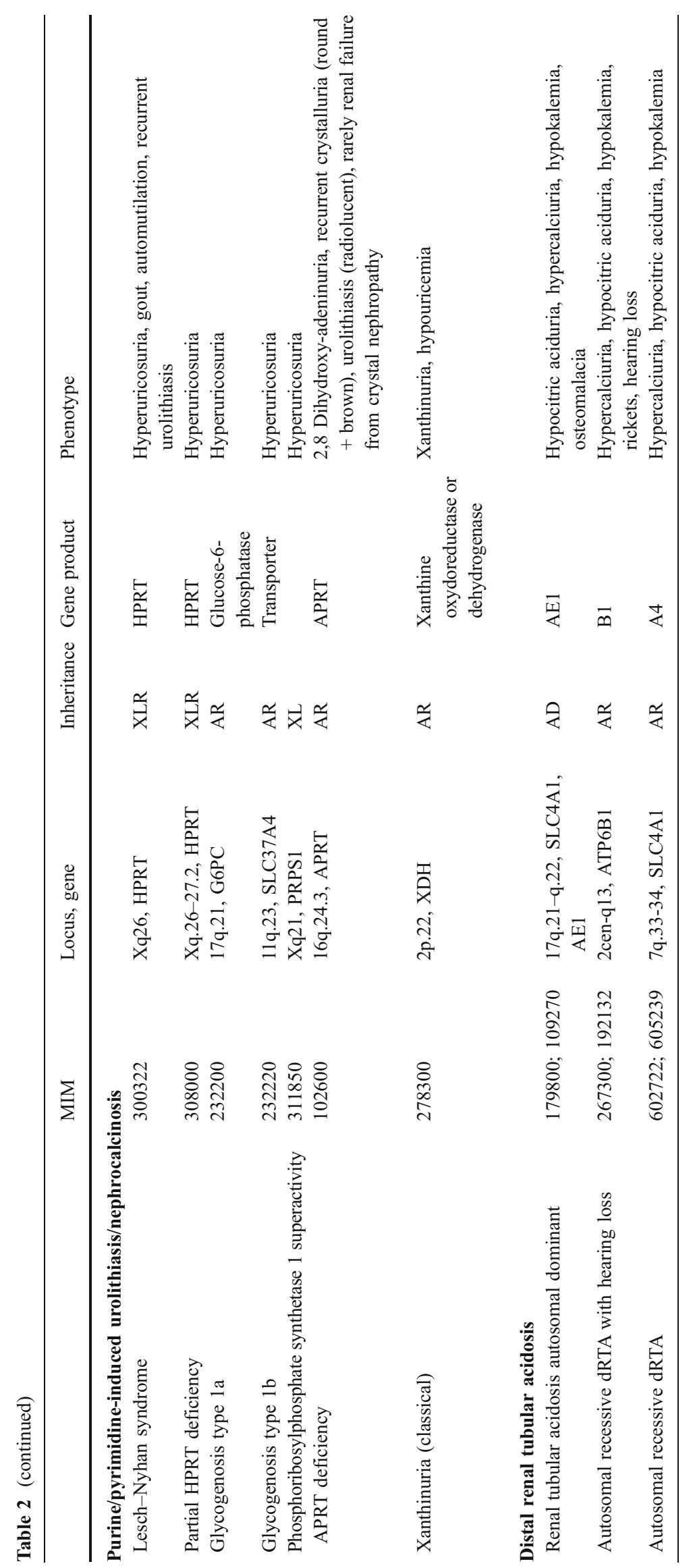


hood. Hence, diagnosis is often only made when nephrocalcinosis is incidentally noted on an imaging study performed for other reasons or when symptoms of reduced concentrating capacity of the renal tubules are obvious. However, the underlying pathological condition is not always evident and requires a detailed history and workup. Renal colic has been reported in some infants with nephrocalcinosis, but it is more likely due to passage of tiny calculi than to nephrocalcinosis per se. It is not unusual for nephrocalcinosis to be diagnosed during systematic renal ultrasound examination of high-risk infants or as part of the diagnostic evaluation of urinary tract infection. The first clinical symptoms, if any, are gross or microscopic hematuria and/or sterile leukocyturia that may be misdiagnosed as urinary tract infection [12].

\section{Diagnostic imaging}

Initial diagnostic testing has to uncover, systematically, obstruction or stasis, infection, and metabolic abnormalities (Tables 1 and 2) and profoundly relies on imaging of the urinary tract. With the availability of minimally invasive imaging modalities, such as ultrasound and computed tomography (CT), the latter less used for pediatric patients, stones are increasingly being detected incidentally during evaluation of nonspecific symptoms or unrelated problems. At baseline, however, imaging of the urinary tract has to be sufficiently thorough to rule out, assertively, stasis or obstruction related either to a stone or to congenital or acquired abnormalities of the urinary tract.

The appearance on imaging studies depends upon the stone's composition. Those composed of calcium oxalate or calcium phosphate have a very dense image on conventional radiographs and on CT scans. Struvite (magnesium ammonium phosphate) and cystine stones are of intermediate density, and small stones of all compositions can be difficult to appreciate by conventional radiography. Uric acid stones are radiolucent on radiographs, requiring the administration of contrast agents for adequate visualization, and have a low density image on CT scans. Stones composed of indinavir, ceftriaxone, sulfadiazine or matrix (all infrequent, the latter composed of protein structures as a matrix for, for example, calcium oxalate stones) are of variable density and may be difficult to differentiate from surrounding soft tissue by any modality, including ultrasound [13-15].

Stones of all composition, with the exception of drugs (e.g. indinavir) and matrix (protein), have distinguishing characteristics of echogenicity and shadowing on ultrasonography. Ultrasonography has the additional advantages of wide availability, avoidance of ionizing radiation, ready detection of hydronephrosis, and ability to define some aspects of the anatomy of the urinary tract. However, ultrasonography is not as sensitive as CT is for the detection of small stones or stones in the ureter. Indeed, small stones may not be detectable by routine ultrasound examination, even when strongly suspected. Measurement of stone size is less reproducible by ultrasound than by conventional radiographs or $\mathrm{CT}$, thus maybe reducing its utility for the monitoring of metabolic stone forming activity over time. Nevertheless, and as stones as small as only $1.5-2 \mathrm{~mm}$ in diameter can be visualized on ultrasonography (US), the success of this imaging method clearly depends on inter-observer and intra-observer variability and skills.

Most stones can be imaged without the use of contrast agents. However, when obstruction is a concern, when radiolucent or low density stones require careful delineation, or when details of urinary tract anatomy are needed (such as confirmation of a duplicated collecting system), contrast agents (CT urography, intravenous pyelography, or retrograde ureteroscopy/pyelography, or orthograde pyelography) are usually required.

Individual clinical characteristics, type of stone, and questions to be addressed should be considered in decisions regarding the best imaging modality. Ultrasonography is almost always a good initial choice and, in uncomplicated situations, may be all that is needed.

The typical stone location is within the renal pelvis and/ or the renal calyces or the ureter and less often within the bladder. The most common ureteral calcification is a stone that has migrated down from the kidney. These stones typically become impacted at anatomic sites of narrowing and are especially difficult to detect when they overlie bony structures such as the sacrum. Detection of a ureteral stone via ultrasonography is difficult, but the stone may lead to obstruction (hydroureter or hydronephrosis) and may, thus, be suspected, even if not directly visualized. Next to that, the color Doppler twinkling artifact can be used in all sides negative for stones in B mode ultrasonography [16].

Studies of adult patients have shown that non-contrastenhanced CT is more effective than intravenous urography (IVU) in identifying and locating ureteral stones [10] and that almost all urinary calculi are now able to be seen with the appropriate selection of imaging techniques, no matter where they reside in the urinary tract [17]. However, in infants and young children, particularly, minimization of exposure to ionizing radiation, and the occasional need for sedation with $\mathrm{CT}$, favors the use of ultrasonography or conventional radiography over $\mathrm{CT}$, whenever they provide the necessary visualization.

For the detecting and monitoring of nephrocalcinosis, high-resolution ultrasonography is the optimal imaging method (Fig. 1). Nephrocalcinosis is classified according to the anatomic area involved. Medullary nephrocalcinosis 
Fig. 1 a Normal, still hyperechoic kidney of a preterm infant; b Tamm-Horsfall kidney; c medullary nephrocalcinosis (NC) grade I (mild increase of echogenicity around the pyramidal border); $\mathbf{d}$ medullary NC grade II (mild increase of echogenicity at whole pyramid); e medullary NC grade III (more severe hyperechogenicity of entire pyramid); $\mathbf{f}$ diffuse corticomedullary NC [6]
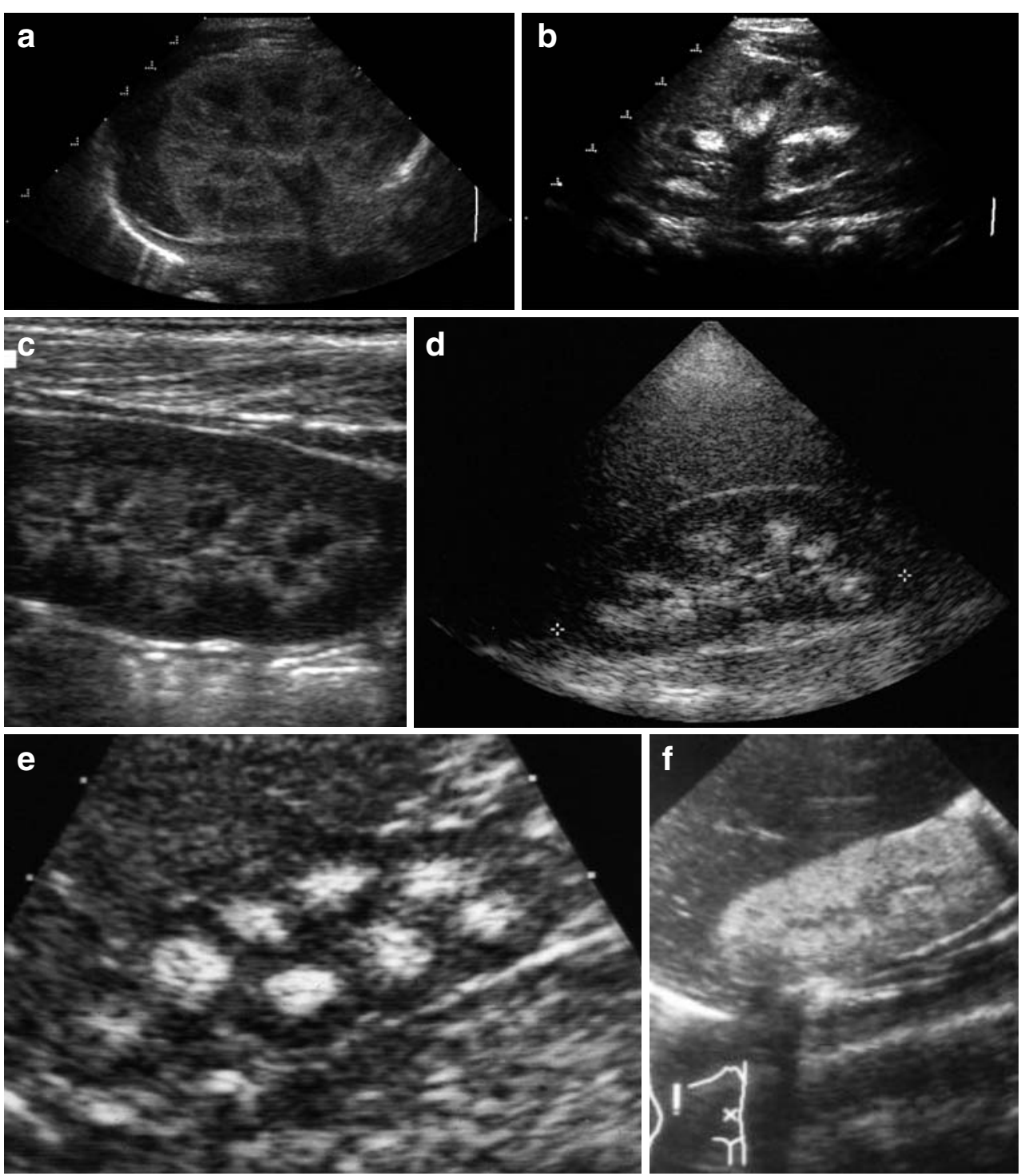

is differentiated from either cortical nephrocalcinosis (e.g. in acute cortical necrosis, chronic glomerulonephritis and chronic graft rejection) or diffuse nephrocalcinosis and is divided into three subtypes according to the degree of echogenicity. Thanks to the routine use of ultrasonography in premature infants and in children at risk, a large number of conditions are now recognized to be associated with nephrocalcinosis (Table 2) [12].

Some pitfalls in the renal ultrasonography of neonates, and especially preterm infants, have to be noted: TammHorsfall protein (THP) deposits within the renal calyces may look like nephrocalcinosis (Fig. 1). THP deposition, however, disappears within 1-2 weeks, and follow-up will show completely normal kidneys. Furthermore, the echogenicity of the renal cortex in neonates is physiologically increased, hence detection of cortical nephrocalcinosis can be difficult and may become evident only some weeks later when a rim of cortical calcification becomes visible.
However, diffuse cortical nephrocalcinosis may already be detectable shortly after birth in patients with suspected primary hyperoxaluria, and it is directly visible both by US and X-ray [18]. Medullary nephrocalcinosis can, sonographically, only be diagnosed when increased echogenicity appears in the area of the renal medulla. Normally, the renal pyramids are hypoechoic in relation to the cortex.

A plain film of the abdomen is less helpful, as only the association of hyperechoic pyramids with a posterior acoustic shadow is a clear sign of nephrocalcinosis. Gross calcifications are thus required before nephrocalcinosis can be diagnosed from conventional radiographs.

A comparison of US and CT in induced nephrocalcinosis in rabbits demonstrated a higher sensitivity for US $(96 \%$ vs $64 \%)$, but a better specificity for CT (96\% vs $85 \%)$ [19]. Still, renal ultrasonography is the first diagnostic imaging option in infants and children with suspected stones or nephrocalcinosis. 
Investigation: examination of urine and blood

Complete urine analysis of a random voided specimen is a necessary diagnostic evaluation in every acute stone episode. Hematuria, white blood cell (WBC) count, pathogens and urinary protein excretion can easily be determined. Microscopic examination of the urine is important, not only for the differentiation between glomerular and non-glomerular hematuria, but also for WBC counts and detection of crystals such as hexagonal cystine crystals, 2,8 dihydroxy-adenine and certain drugs (e.g. indinavir urinary crystals [20]). Since the $\mathrm{pH}$ of the urine is a major factor in the formation of many stones, its measurement-preferably by glass electrode, or, if a $\mathrm{pH}$ electrode is not available, by $\mathrm{pH}$ paper with the specific and adequately distinguishable range of $\mathrm{pH} 2$ to 9 -is of utmost importance. Sometimes, it is advisable to determine a daily profile of both the $\mathrm{pH}$ and the density (specific gravity or osmolality) of the urine. This may also be used for follow-up, e.g. to assess the effect of the administration of alkali or to check the patient's compliance regarding sufficient fluid intake. The presence or absence of infection can be addressed by a urine culture.

Chemical analysis includes, apart from creatinine, calcium, uric acid, oxalic acid, phosphate [determine tubular reabsorption of phosphate (TRP) or tubular maximum for

Table 3 Normal values for $24 \mathrm{~h}$ urine collection (there should be preservative in the container, either thymol $5 \%$ in isopropanol, or $2 \mathrm{~N}$ hydrochloric acid $(\mathrm{HCl})$, before collection is started). Repeat collection after stone has been captured, as ongoing stone formation may phosphate corrected for glomerular filtration rate $(\mathrm{TmP} /$ GFR)], magnesium and citrate. Cystine is screened for by nitroprusside test or by chromatography for amino acids. For all patients, analyses for serum calcium, phosphorus, magnesium, uric acid, alkaline phosphatase, $\mathrm{pH}$, bicarbonate, and creatinine should be performed. In specific cases further blood analyses for parathyroid hormone (PTH), vitamin D metabolites, vitamin A (for patients with hypercalciuria), serum vitamin B6 levels and plasma oxalate (for patients with primary hyperoxaluria) and, of course, molecular genetic testing (see Tables 1 and 2) will later be necessary.

Predisposing causes for urolithiasis can be recognized in $>75 \%$ of children and adolescents with urinary tract stones $[7,9]$. Accordingly, every young patient with urolithiasis, and even with the first stone episode, deserves a comprehensive examination so that a delay in treatment, and hence early complication, e.g. acute renal failure in infantile oxalosis, can be avoided $[6,11]$. Infection, obstruction, or stasis will be identified by the diagnostic evaluation outlined above. However, systematic detection of predisposing metabolic factors requires further testing.

Metabolic factors, among which hypercalciuria, hyperoxaluria and hypocitraturia are the most common, are determined by measurement of relevant urinary solutes and naturally occurring inhibitors of crystal and stone forma-

diminish lithogenic excretion parameters. Check urine volume and creatinine excretion $(2 \mathrm{mg} / \mathrm{kg} \pm 0.8 \mathrm{mg})$ to ensure adequate collection [5, 6, 36-41]. FHHNC Familial hypomagnesemia and hypercalciuria with nephrocalcinosis syndrome, $F E_{M g}$ fractional excretion of magnesium

\begin{tabular}{lll}
\hline Parameter age & Normal value per $24 \mathrm{~h}$ & Remarks \\
\hline Calcium, all ages & $<0.1 \mathrm{mmol}(<4 \mathrm{mg}) / \mathrm{kg}$ & See Table 2 \\
Oxalate & $<0.5 \mathrm{mmol}(<45 \mathrm{mg}) / 1.73 \mathrm{~m}^{2}$ & $\begin{array}{c}\text { Primary hyperoxaluria types I/II for constant excessive } \\
\text { elevation, check also urinary glycolate, L-glycerate and } \\
\text { plasma oxalate } \\
\end{array}$ \\
& & $\begin{array}{l}\text { Secondary hyperoxaluria: determine intestinal oxalate } \\
\text { absorption and stool. Oxalobacter formigenes colonization. }\end{array}$ \\
& $\begin{array}{l}\text { Normal plasma oxalate different according to laboratory } \\
\text { method, but clearly }<8 \mu \text { mol/1 }\end{array}$
\end{tabular}

\footnotetext{
Citrate

Male

Female

Uric acid, all

ages

Magnesium

Phosphate

$<3$ months

$<6$ months

2-15 years

Cystine

$<10$ years

$>10$ years

Adults
}

\author{
$>1.9 \mathrm{mmol}(365 \mathrm{mg}) / 1.73 \mathrm{~m}^{2}$ \\ $>1.6 \mathrm{mmol}(310 \mathrm{mg}) / 1.73 \mathrm{~m}^{2}$ \\ $0.56 \mathrm{mg} / \mathrm{dl}$ per GFR \\ $>0.04 \mathrm{mmol}(0.8 \mathrm{mg}) / \mathrm{kg}$ \\ $\mathrm{TmP} / \mathrm{GFR}$ \\ $<3.3 \mathrm{mmol} / 1$ \\ $<2.6 \mathrm{mmol} / 1$ \\ $<2.44 \mathrm{mmol} / 1$ \\ $<55 \mu \mathrm{mol}(13 \mathrm{mg}) / 1.73 \mathrm{~m}^{2}$ \\ $<200$ (48 mg) \\ $<250,(60 \mathrm{mg})$
}

Cystine solubility threshold 160-320 mg cystine/ at pH 5-7
Hypocitraturia: metabolic acidosis, hypokalemia, calcineurin inhibitors

Hyperuricosuria: check diet, medication, tumor lysis, inborn errors of metabolism

FHHNC with hypomagnesemia and elevated $\mathrm{FE}_{\mathrm{Mg}}$, See Table 2 Renal phosphate leakage with low serum phosphate, tumor lysis syndrome with high serum phosphate

Check morning urine for hexagonal crystals 
Table 4 Normal values for spot urine samples: creatinine ratios (solute/creatinine). Ratios are more prone to error than are timed samples. Interpret with respect to daytime, relation to meals, diet, medication, age and regional differences $[5,6,36-41]$ ( $C a$ calcium, $R T A$ renal tubular acidosis)

\begin{tabular}{|c|c|c|c|}
\hline \multirow{3}{*}{$\begin{array}{l}\text { Parameter age } \\
\text { Calcium } \\
<12 \text { months }\end{array}$} & \multicolumn{2}{|c|}{ Ratio of solute to creatinine } & \multirow{3}{*}{ Remarks } \\
\hline & $\mathrm{mol} / \mathrm{mol}$ & $\mathrm{mg} / \mathrm{mg}$ & \\
\hline & $<2$ & 0.81 & \\
\hline $1-3$ years & $<1.5$ & 0.53 & \\
\hline $1-5$ years & $<1.1$ & 0.39 & \\
\hline $5-7$ years & $<0.8$ & 0.28 & \\
\hline$>7$ years & $<0.6$ & 0.21 & \\
\hline \multirow{3}{*}{$\begin{array}{l}\text { Oxalate } \\
0-6 \text { months } \\
7-24 \text { months }\end{array}$} & $\mathrm{mmol} / \mathrm{mol}$ & $\mathrm{mg} / \mathrm{g}$ & \multirow{6}{*}{$\begin{array}{l}\text { Primary hyperoxaluria types I/II for constant excessive elevation, check also urinary } \\
\text { glycolate, L-glycerate and plasma oxalate. Secondary hyperoxaluria: determine } \\
\text { intestinal oxalate absorption and stool Oxalobacter formigenes colonization }\end{array}$} \\
\hline & $<325-360$ & $288-260$ & \\
\hline & $<132-174$ & $110-139$ & \\
\hline $2-5$ years & $<98-101$ & 80 & \\
\hline $5-14$ years & $<70-82$ & $60-65$ & \\
\hline$>16$ years & $<40$ & 32 & \\
\hline Citrate & $\mathrm{mol} / \mathrm{mol}$ & $\mathrm{g} / \mathrm{g}$ & \multirow[t]{3}{*}{ Low with tubular dysfunction: RTA, prematurity, hypokalemia, renal transplantation } \\
\hline $0-5$ years & $>0.25$ & 0.42 & \\
\hline$>5$ years & $>0.15$ & 0.25 & \\
\hline \multirow[t]{2}{*}{ Magnesium } & $\mathrm{mol} / \mathrm{mol}$ & $\mathrm{g} / \mathrm{g}$ & \multirow[t]{2}{*}{ For $<2$ years, no reliable data } \\
\hline & $>0.63$ & $>0.13$ & \\
\hline $\begin{array}{l}\text { Uric acid } \\
>2 \text { years }\end{array}$ & \multicolumn{2}{|c|}{$\begin{array}{l}<0.56 \mathrm{mg} / \mathrm{dl}(33 \mu \mathrm{mol} / \mathrm{l}) \text { per } \mathrm{GFR} \\
(\text { ratio } \times \text { plasma creatinine })\end{array}$} & Higher than in adults throughout childhood; no reliable data for age $<2$ years \\
\hline
\end{tabular}

tion, such as citrate. Blood levels of calcium and other analytes, as determinants of urine composition or as indicators of underlying disorders relevant to stone formation (such as metabolic acidosis), are also of importance.

Since many urinary components are influenced by dietary intake, $24 \mathrm{~h}$ urine collections (to exclude diurnal fluctuations related to intake of food and beverages) provide the best information and also provide an objective assessment of the child's daily intake of fluid. Advise the patient or the parent to maintain the normal fluid intake and the normal dietary habits, and, meanwhile, $24 \mathrm{~h}$ urine should be collected. Next, avoid urine sampling under parenteral infusions. Also keep in mind that stones in situ may diminish the excretion of urinary lithogenic material, as these substances may concurrently be absorbed by the stone [21]. For urine collection, a preservative should ideally be placed directly into the sampling bottle; however, urine may be collected without initial preservation, so long as it is kept cool (at $4^{\circ} \mathrm{C}$ ) and adequately preserved within $24 \mathrm{~h}$ [22].

In infants or young children, or in situations where a $24 \mathrm{~h}$ urine collection is difficult, random urine measurements, using the ratio of the concentration of each analyte to that of urine creatinine, provide valuable information. Again, the best results are obtained if urine is collected while patients are receiving their usual diets and fluid intake. Bladder catheterization only for $24 \mathrm{~h}$ urine collection should be avoided, especially for boys.

Erroneous results might be obtained if obstruction or infection is present, or when stone fragments are being passed in the urine following a recent stone fragmentation procedure. Analysis should be deferred until infection has been treated and until at least 1 month after lithotripsy or resolution of the obstruction [23].

Normal values for the excretion rates of solutes that are most often implicated in stone formation are shown in Tables 3 and 4. However, it has to be kept in mind that such data clearly show regional and cultural variability, and, so far, no multi-institutional studies regarding normative data of pediatric excretion values exist. Specific abnormalities may dictate a more directed testing. Many children and adolescents with stones have more than one predisposing

Table 5 Ten take-home messages

\section{Message}

1. Kidney stones/nephrocalcinosis in children are the symptoms of a disease, not the disease itself

2. About $40 \%$ of children with urolithiasis have a positive family history

3. Predisposing causes for urolithiasis can be recognized in $75 \%$ of

children and adolescents

4. Unexplained sterile pyuria or recurrent UTI should raise the suspicion for urolithiasis

5. Gross hematuria may precede manifest urolithiasis or nephrocalcinosis

6. Nephrocalcinosis is mostly asymptomatic

7. The diagnosis of primary hyperoxaluria is often delayed; early detection may prevent the development of renal failure

8. Calyceal depositions of Tamm-Horsfall protein are harmless, but they may mimic nephrocalcinosis in (preterm) neonates

9. Metabolic urine analysis should be performed in $24 \mathrm{~h}$ urine collection 10. Passing stone fragments and UTI may hamper proper metabolic urine analysis 
factor [24]. With that in mind, it is important to complete a systematic evaluation, even when the etiology seems obvious. For example, patients with congenital ureteropelvic junction obstruction and stones may have hypercalciuria as a second predisposing cause. When an inherited metabolic disorder is suspected, urine samples from family members can be of help in the primary diagnosis, and they are also valuable for detection in affected family members.

For patients with multiple stones at the onset, or those in whom there is active stone formation and no abnormalities have been identified, additional testing can be helpful. This testing should include a timed (preferably $24 \mathrm{~h}$ ) urine collection for a full supersaturation profile $[25,26]$. Owing to day-to-day variations in diet and fluid intake, three separate determinations on different days have been demonstrated to provide the best information [27]. However, the value of such computer-based calculation of urinary saturation is debatable, as are other determinants of stone risk factors, such the BONN risk index (BRI, [28, 29]).

In patients with hyperoxaluria, intestinal absorption of oxalate may be increased, either due to an increased intake of dietary oxalate, or for enteric reasons such as chronic inflammatory bowel diseases or a lack of intestinal oxalatedegrading bacteria [30]. Next to that, the pathology of intestinal oxalate transporters, e.g. those of the solute carrier family (SLC26A6), may also play an important role, which is currently under specific evaluation [31]. To discriminate the primary from the secondary forms of hyperoxaluria better, a $\left[{ }^{13} \mathrm{C}_{2}\right]$ oxalate absorption test can be performed, which is safe and reliable in children, as in adults. Intestinal oxalate absorption is normal in patients with primary hyperoxaluria and would be significantly increased in those with dietary or enteric hyperoxaluria [32]. Also, a stool analysis for the absence of oxalate-degrading bacteria, especially Oxalobacter formigenes, will give further evidence of the existence of a secondary reason for hyperoxaluria [33].

\section{Stone analysis}

Qualitative analysis of the stone obtained after spontaneous stone passage or intervention is one of the most important diagnostic measures. Only one-third of all stones are composed of one single substance, and all components should, hence, be determined. The methods of choice are infrared spectroscopy or X-ray diffraction. Even amounts of less then $1 \mathrm{mg}$ can be analyzed. Chemical stone analysis is inappropriate, as it is prone to errors and is obsolete. The analytic principle of X-ray diffraction is based on the crystal structure of the stone substances. With infrared spectroscopy the loss of energy in the infrared spectrum due to the circulation of the activated chemical molecules is determined.
The diagrams of either method (the so-called fingerprints) provide an exact analysis [34].

Recurrent stones should be analyzed again, since the stone composition may change. After lithotripsy only stone fragments are available, and these can be recovered by straining the urine. All fragments should be sent for analysis to allow additional tests, if needed.

With regard to treatment regimens, all stone components are of importance. Apart from the main stone components there are several other substances, such as salts of uric acid (urates), rare calcium phosphate compositions, protein matrix stones, stones comprised of medications or their metabolites (e.g. indinavir, ceftriaxone, sulfadiazine), and artifacts like gypsum or seeds.

\section{Conclusions}

Pediatric urolithiasis is not as rare as is generally believed. In addition, the prevalence of nephrocalcinosis may be high, especially in preterm infants [35]. Hence, thorough and early diagnostic examination is mandatory, for every infant or child with the first stone event or with nephrocalcinosis (see Table 5). Following this advice, recurrence of stone disease or progression of nephrocalcinosis can be prevented, or, taking the worst scenario into consideration, prevention of early end-stage renal failure (e.g. in patients with primary hyperoxaluria), can be achieved.

\section{Questions}

(Answers appear following the reference list)

1. Which of the following statements are true? Urolithiasis in children is

a. more frequent than in adults

b. has the same frequency as in adults

c. is less frequent than in adults (approximately $10 \%$ the rate of adults) but is often under-diagnosed

d. more frequent in boys than in girls

e. all of the above are true

2. A metabolic cause of urolithiasis

a. is more likely in children than in adults, since family history is often positive

b. is unlikely, since the most frequent etiology is UTI

c. can easily be ruled out by family history

d. has the same frequency as in adults

e. does not require consideration, since urolithiasis in children is so rare

3. Which of the following is not true? Symptoms of urinary tract stones may include

a. gross hematuria

b. pain 

c. vomiting
d. fever
e. isolated proteinuria

4. Risk factors for urolithiasis in children include
a. dehydration
b. gastro-intestinal disorders (e.g. Crohn's disease)
c. urinary tract infections
d. diet
e. all of the above are true

5. Primary hyperoxaluria type 1 is
a. a serious disorder that can cause urolithiasis but also end-stage renal disease
b. the most frequent cause of urolithiasis in children
c. always associated with hypercalciuria
d. only likely if family history is positive
e. a benign condition that does not require treatment

6. Imaging studies in urolithiasis
a. are not important, since clinical details indicate localization
b. should be thorough, since stones may be small and are difficult to detect
c. should always include intravenous pyelography
d. should only include abdominal CT, since conven- tional radiology is mostly insufficient
e. all of the above are true

7. Which of the following are true? The investigation of metabolic causes in children should include
a. hypercalciuria
b. hypocitraturia
c. hypertriglyceridemia
d. phenylketonuria
e. cystinuria

\section{References}

1. López M, Hoppe B (2008) History, epidemiology and regional diversities of urolithiasis. Pediatr Nephrol doi:10.1007/s00467008-0960-5

2. Hesse A (2005) Reliable data from diverse regions of the world exist to show that there has been a steady increase in the prevalence of urolithiasis (editorial). World J Urol 23:302-303

3. Sarica K (2006) Pediatric urolithiasis: etiology, specific pathogenesis and medical treatment. Urol Res 34:96-101

4. Edvardsson V, Elidottir H, Indridason OS, Palsson R (2005) High incidence of kidney stones in Icelandic children. Pediatr Nephrol 20:940-944

5. Leumann E, Hoppe B (1997) Urolithiasis in childhood. In: Proesmanns W (ed) Therapeutic strategies in children with renal disease, vol 5. Bailliere's Clinical Paediatrics, London, pp 655-674

6. Hoppe B, Milliner D, Leumann E (2008) Urolithiasis and nephrocalcinosis in childhood. In: Geary D, Schaefer F (eds) Comprehensive pediatric nephrology, chapter 33. Mosby, Elsevier, Philadelphia, pp 499-525

7. Van't Hoff WG (2004) Aetiological factors in paediatric urolithiasis. Nephron Clin Pract 98:c45-c48
8. Stapleton FB (1996) Clinical approach to children with urolithiasis. Semin Nephrol 3:116-124

9. Cameron MA, Sakkhae K, Moe OW (2005) Nephrolithiasis in children. Pediatr Nephrol 20:1587-1592

10. Smith RC, Rosenfield AT, Choe KA, Essenmacher KR, Verga M, Glickman MG, Lange RC (1995) Acute flank pain: comparison of non-contrast-enhanced CT and intravenous urography. Radiology 194:789-794

11. Van Woerden CS, Groothoff JW, Wanders RJ (2003) Primary hyperoxaluria type 1 in The Netherlands: prevalence and outcome. Nephrol Dial Transplant 18:273-279

12. Alon US (1997) Nephrocalcinosis. Pediatrics 9:160-165

13. Sandersius S, Rez P (2007) Morphology of crystals in calcium oxalate monohydrate kidney stones. Urol Res 35:287-293

14. Mohkam M, Karimi A, Gharib A, Daneshmand H, Khatami A, Ghojevand N, Sharifian M (2007) Ceftriaxone associated nephrolithiasis: a prospective study in 284 children. Pediatr Nephrol 22:690-694

15. Catalano-Pons C, Bargy S, Schlecht D, Tabone MD, Deschenes G, Bensman A Ulinski T (2004) Sulfadiazine induced nephrolithiasis in children. Pediatr Nephrol 19:928-931

16. Turrin A, Minola P, Costa F, Cerati L, Andrulli S, Trinchieri A (2007) Diagnostic value of colour Doppler twinkling artefact in sites negative for stones on B mode renal sonography. Urol Res 35:313-317

17. Mindell HJ, Cochran ST (1994) Current perspectives in the diagnosis and treatment of urinary stone disease. Am J Radiol 163:1314-1315

18. Benz-Bohm G, Hoppe B (2008) Urolithiasis and nephrocalcinosis. In: Fotter R (ed) Pediatric uroradiology. Springer, Heidelberg, pp 385-400

19. Cramer B, Husa L, Pushpanathan C (1998) Nephrocalcinosis in rabbits - correlation of ultrasound, computed tomography, pathology and renal function. Pediatr Radiol 28:9-13

20. Gagnon RF, Tsoukas CM, Watters AK (1998) Light microscopy of indinavir urinary crystals (letter). Ann Int Med 128:321

21. Laube N, Pullmann M, Hergarten S, Schmidt M, Hesse A (2003) The alteration of urine composition due to stone material present in the urinary tract. Eur Urol 44:595-599

22. van Woerden CS, Huidekoper HH, Groothoff JW, Wijburg FA, Duran M (2007) Postponing urine acidification for $24 \mathrm{~h}$ does not change the oxalate concentration. Clin Chim Acta 384:184-185

23. Beck B, Hoppe B (2005) Pediatric aspects of nephrolithiasis and nephrocalcinosis. In: Chaussy C, Haupt G, Jocham D, Köhrmann $\mathrm{KU}$, Wilbert D (eds) Therapeutic energy applications in urology. Thieme, Heidelberg, pp 86-91

24. Habbig S, Kratz J, Beck B, Feldkötter M, Taylan C, Körber F, Hoppe B (2008) Nephrocalcinosis and nephrolithiasis in children: is hypercalciuria the most important risk factor? J Am Soc Nephrol Abstr (in press)

25. Battino BS, DeFoor W, Coe F, Tackett L, Erhard M, Wacksman J, Sheldon CA, Minevich E (2002) Metabolic evaluation of children with urolithiasis: are adult references for supersaturation appropriate. J Urol 168:2568-2571

26. Defoor W, Asplin J, Jackson E, Jackson C, Reddy P, Sheldon C, Minevich E (2005) Results of a prospective trial to compare normal urine supersaturation in children and adults. J Urol 174:1708-1710

27. Parks JH, Goldfisher E, Asplin JR, Coe FL (2002) A single 24hour urine collection is inadequate for the medical evaluation of nephrolithiasis. J Urol 167:1607-1612

28. Laube N, Hoppe B, Hesse A (2005) Problems in the investigation of urines from patients suffering from primary hyperoxaluria type I. Urol Res 33:394-397

29. Porowski T, Zoch-Zwierz W, Konstantynowicz J, Taranta-Janusz K (2008) A new approach to the diagnosis of children's urolithiasis based on the Bonn risk index. Pediatr Nephrol 23:1123-1128 
30. Hoppe B, Leumann E, von Unruh G, Laube N, Hesse A (2003) Diagnostic and therapeutic approaches in patients with secondary hyperoxaluria. Front Biosci 8:e437-e443

31. Hatch M, Freel RW (2008) The roles and mechanisms of intestinal oxalate transport in oxalate homeostasis (review). Semin Nephrol 28:143-151

32. Sikora P, von Unruh GE, Beck B, Feldkötter M, Zajączkowska M, Hesse A, Hoppe B (2008) [(13)C(2)]oxalate absorption in children with idiopathic calcium oxalate urolithiasis or primary hyperoxaluria. Kidney Int 73:1181-1186

33. Kaufman DW, Kelly JP, Curhan GC, Anderson TE, Dretler SP, Preminger GM, Cave DR (2008) Oxalobacter formigenes may reduce the risk of calcium oxalate kidney stones. J Am Soc Nephrol 19:1197-1203

34. Hesse A (2002) Urinary calculi 1: epidemiology, laboratory diagnosis, genetics and infections. Urologe A 41:496-508

35. Sikora P, Roth B, Kribs A, Michalk DV, Hesse A, Hoppe B (2003) Hypocitraturia is one of the major risk factors for nephrocalcinosis in very low birth weight (VLBW) infants. Kidney Int 63:21942199

36. de Santo NG, Di Iorio B, Capasso G, Paduano C, Stamler R, Langman CB, Stamler J (1992) Population based data on urinary excretion of calcium, magnesium, oxalate, phosphate and uric acid in children from Cimitile (souther Italy). Pediatr Nephrol 6:149157

37. Hoppe B, Jahnen A, Bach D, Hesse A (1997) Urinary calcium oxalate saturation in healthy infants and children. J Urol 158:557-559

38. Leumann EP, Dietl A, Matasovic A (1990) Urinary oxalate and glycolate excretion in healthy infants and children. Pediatr Nephrol 4:493-497

39. Brodehl J, Krause A, Hoyer P (1988) Assessment of maximal tubular phosphate reabsorption: comparison of direct measurement with the nomogram of Bijvoet. Pediatr Nephrol 2:193-198

40. Payne RB (1998) Renal tubular reabsorption of phosphate (TmP/ GFR): indications and interpretation. Ann Clin Biochem 35:201206

41. Stapleton FB, Nash DA (1983) A screening test for hyperuricosuria. J Pediatr 102:88-90

\footnotetext{
Answers

1. Correct answers are $\mathrm{c}$ and $\mathrm{d}$ :

The incidence of urolithiasis in childhood is believed to be approximately $10 \%$ of that in adults, which is around $5 \%$ in industrialized countries [2]. As a significant proportion of patients remains undiagnosed or misdiagnosed (incidental discovery is reported in $15-40 \%$ ), numbers should be interpreted with caution. Urolithiasis appears in all age groups of children, but a male predominance analogous to that in adult patients is observed.
}

\section{Correct answer is a:}

About $40 \%$ of children with urolithiasis have a positive family history of kidney stones, and most of the children have a metabolic background of stone disease. Hence, specific and intensive diagnostic examination is necessary for every child experiencing even a single kidney stone to prevent recurrence of disease or even a disastrous outcome, with kidney failure and end-stage renal disease.

3. Correct answer is e:

The most common symptom of urolithiasis is abdominal pain, in older children clearly identifiable as colicky pain, in infants and children, however, only recognized as "non-specific" abdominal pain and thus difficult to differentiate from acute appendicitis, etc. Unexplained sterile pyuria or recurrent urinary tract infections should raise the level of suspicion for urolithiasis, especially in the younger child. Gross or microscopic (non-glomerular) hematuria and, more rarely, flank tenderness or urinary retention, are other symptoms encountered. Hematuria may be present for some time before urolithiasis or nephrocalcinosis becomes manifest. Sometimes, there are secondary gastro-intestinal tract symptoms, such as vomiting, flatulence or constipation.

4. Correct answer is e:

Regarding the risk of nephrolithiasis or nephrocalcinosis, particular attention has to be paid to nutrition or specific diets, fluid intake (dehydration), medications (vitamins D/A, steroids, diuretics, etc.) and any mineral supplementation. Children with chronic bowel disease (e.g. Crohn's disease, cystic fibrosis, post-bowel resection), neurologic disorders (anticonvulsant drugs, low fluid intake) or with anomalies of the urinary tract predisposing to urine stasis and urinary tract infection (neurogenic bladder, ileal loops, megaureter, megacalycosis, hydronephrosis) are at special risk of stone formation.

5. Correct answer is a:

Primary hyperoxaluria type I is an autosomal-recessive inherited disorder which leads to recurrent nephrolithiasis and/or progressive nephrocalcinosis and can lead to early end-stage renal failure in those patients with severe symptoms (infantile oxalosis).

6. Correct answer is b:

Initial diagnostic testing has to uncover obstruction or stasis, infection, and metabolic abnormalities systematically (Table 1), and it relies profoundly on imaging of the urinary tract. With the availability of minimally invasive imaging modalities such as ultrasound and CT, the latter less used for pediatric patients, stones are being increasingly detected incidentally during evaluation of nonspecific symptoms or unrelated problems. At baseline, however, imaging of the urinary tract has to be sufficiently thorough to rule out, assertively, stasis or obstruction related either to a stone or to congenital or acquired abnormalities of the urinary tract. Intravenous urography is not a method of choice for the pediatric patient.

7. Correct answers are $\mathrm{a}, \mathrm{b}$ and $\mathrm{e}$ :

Chemical analysis includes, apart from creatinine, calcium, uric acid, oxalic acid, phosphate, magnesium and citrate. Cystine is screened for by nitroprusside test or by chromatography for amino acids. For all patients, analysis of serum calcium, phosphorus, magnesium, uric acid, alkaline phosphatase, $\mathrm{pH}$, bicarbonate, and creatinine should be performed. 